\title{
Recovery of Danish Coastal Ecosystems After Reductions in Nutrient Loading: A Holistic Ecosystem Approach
}

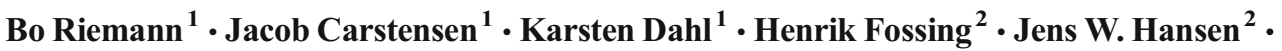 \\ Hans H. Jakobsen ${ }^{1}$ • Alf B. Josefson ${ }^{1}$ • Dorte Krause-Jensen ${ }^{2}$ - Stiig Markager ${ }^{1}$. \\ Peter A. Stæhr ${ }^{1}$ • Karen Timmermann ${ }^{1}$ • Jørgen Windolf ${ }^{2}$ • Jesper H. Andersen ${ }^{3}$
}

Received: 4 February 2015 /Revised: 23 April 2015 / Accepted: 28 April 2015 / Published online: 9 May 2015

(C) The Author(s) 2015. This article is published with open access at Springerlink.com

\begin{abstract}
In the 1980s, Danish coastal waters suffered from eutrophication and several nutrient management plans have been implemented during the years to improve ecological status. This study aims at giving a holistic ecosystem perspective on 25 years of mitigation measures. We report trends of nutrient inputs and the responses to these in various chemical and biological components. Nutrient inputs from land were reduced by $\sim 50 \%$ for nitrogen $(\mathrm{N})$ and $56 \%$ for phosphorus (P) since 1990. These reductions resulted in significant and parallel declines in nutrient concentrations, and initiated a shift in the dominance of primary producers towards reduced phytoplankton biomass (chlorophyll $a$ concentration) and increased cover of macroalgae in deeper waters. In the last 5 years, eelgrass meadows have also expanded towards deeper waters, in response to improving water clarity. An expected improvement of bottom water oxygen conditions has not been observed, presumably because more frequent stratification and higher water temperatures have counteracted the expected positive effects of reduced nutrient inputs. The biomass of the benthic macrofauna decreased as expected, but it was composed of a drastic decline of filter feeders paralleled by a more moderate increase of deposit feeders. This shift was most likely induced by increasing stratification. The reduced benthic
\end{abstract}

Communicated by Marianne Holmer

Bo Riemann

bri@bios.au.dk

1 Department of Bioscience, Aarhus University, Frederiksborgvej 399, 4000 Roskilde, Denmark

2 Department of Bioscience, Aarhus University, Vejlsøvej 25, 8600 Silkeborg, Denmark

3 NIVA Denmark Water Research, Ørestads Boulevard 73, 2300 Copenhagen S, Denmark filtration along with the limited eelgrass cover probably kept relatively more particles in suspension, which can explain why improvements in the Secchi depths were modest. Overall, several ecosystem components demonstrated clear signs of improvement, suggesting that at least partial recovery is attainable. On this basis, we propose a conceptual scheme for recovery of shallow coastal ecosystems following marked reductions in nutrient inputs.

Keywords Benthic macrofauna $\cdot$ Eelgrass $\cdot$ Macroalgae Nutrients · Oligotrophication · Recovery · Water quality

\section{Introduction}

Eutrophication from nutrient over-enrichment has deteriorated coastal ecosystems worldwide (Conley et al. 2000; Cloern 2001; Boesch 2002; Kemp et al. 2005a, b). The effects include a series of changes starting with increased pelagic primary production which initiates a cascade of processes leading to increased phytoplankton biomass (Cloern 2001), reduced water clarity, reduced benthic primary production (Sand-Jensen and Borum 1991; Duarte 1995), and increased secondary production of benthos in areas not affected by oxygen deficiency (Josefson and Rasmussen 2000). In addition, eutrophication stimulates development of harmful algal blooms, hypoxia in bottom waters, associated fish kills, and severe changes in pelagic and benthic food web structure, including reduced species richness in areas affected by oxygen deficiency (e.g., Conley et al. 2007) and overall changes of biogeochemical pathways (Boesch et al. 2001; Kemp et al. 2005a, b; Carstensen et al. 2014). All these changes in the functioning of the coastal ecosystems also influence ecosystem services and associated activities, including tourism and commercial and recreational fisheries. 
Danish estuaries and coastal waters were markedly affected by eutrophication during the twentieth century. Increasing nutrient inputs from agriculture, industry, and urban areas were discharged into these shallow marine environments, accelerating between 1950 and the mid-1980s, and resulting in all the well-known signs of eutrophication (Conley et al. 2000; Carstensen et al. 2006; Conley et al. 2007). Atmospheric deposition was negligible compared to other sources. Particularly, events of widespread oxygen depletion in the 1980s prompted political action. Since 1985, a number of Danish mitigation measures have been implemented to reduce nutrient losses from three sectors: (i) agriculture, (ii) urban waste water treatment plants, and (iii) industries with separate discharge. The first national Action Plan for the Aquatic Environment (APAE) was enacted in 1987, followed by other APAEs in the following decades including more efficient nutrient management measures to achieve an overall objective of reducing nitrogen $(\mathrm{N})$ and phosphorus $(\mathrm{P})$ discharges by 50 and $80 \%$, respectively (Kronvang et al. 2008). Whereas the first APAE was effectively targeting point sources, the following action plans were more directed towards diffuse sources.

The Danish APAEs as well as European directives such as the Water Framework Directive rest on the fundamental tenets that ecosystem degradation is a fully reversible process and hence, that ecosystems can be recovered to an environmental healthy state upon removal of pressures following the same pressure-state relationships during degradation and recovery. However, while the eutrophication process leading to ecosystem degradation is well studied and understood, our knowledge on coastal ecosystem recovery following significant nutrient reductions is limited and suffers from scarcity of longterm large-scale ecosystem studies. Existing studies indicate that complete recovery of coastal ecosystems to a previous baseline is rarely a realistic assumption (Lotze et al. 2011; Duarte et al. 2015) because degradation and recovery typically follow different non-linear pressure-response pathways and the interaction of multiple pressures may lead to shifts in baseline conditions (Duarte et al. 2009; Carstensen et al. 2011; Taylor et al. 2011).

Alternative stable regimes, i.e., the differential response to the same pressure level depending on ecosystem state, has been identified as a widespread phenomenon in coastal ecosystems (Duarte et al. 2009; Kemp et al. 2009) that can delay recovery for decades (Borja et al. 2010; Jones and Schmitz 2009) or even centuries (Gonzales-Correa et al. 2005). Such hysteresis effect results from the existence of stable states being buffered by feedback mechanisms (Scheffer and Carpenter 2003; Duarte et al. 2009; Kemp et al. 2009), and implies that pressures need to be reduced beyond the threshold levels originally causing the degradation in order to allow recovery. For example, positive feedbacks exist between dense seagrass meadows, sediment stability, and water clarity and act to stabilize the seagrass state, but if the meadows are lost, the bare state is buffered by sediment resuspension and high turbidity which impede reestablishment of seagrass, and as a result two alternative states can exist at the same pressure level (Carr et al. 2010; van der Heide et al. 2011). Other examples of buffering mechanisms include barriers to internal recycling of nutrients and release of hydrogen sulfide from sediments (Carstensen et al. 2014), and control of algal biomass by herbivores (Cloern et al. 2007). Once the ecosystem is altered by nutrient over-enrichment, the nature of buffering processes is altered and hence difficult to re-establish (Kemp et al. 2005a, b). Degradation and recovery therefore typically follow different non-linear pathways or trajectories (Munkes 2005; Kemp et al. 2009; Villnäs et al. 2011), with only few examples of full recovery (Greening et al. 2011; Carstensen et al. 2013).

In addition, coastal ecosystems affected by eutrophication may become more sensitive to other pressures such as climate change and fishery (Justíc et al. 1996; Baden et al. 2012), reducing the rate of recovery and likely altering achievable restoration targets (Carstensen et al. 2013). Consequently, the use of conceptual and numerical models to test recovery and restoration scenarios as well as legislative frameworks focusing on specific targets, measures, and tolerable deviations often lack information from empirical data for validation.

Here, we present a data-driven long-term analysis and narrative of recovery of temperate coastal marine ecosystems in Denmark. We present results from a large-scale nutrient reduction experiment initiated through the Danish APAEs. The study covers a period starting with excessive nutrient inputs during the 1980s (Conley et al. 2007) and describes coastal ecosystem responses to measures taken to reduce nutrient inputs (Kronvang et al. 2008). During the last three decades, agricultural practices have changed and sewage treatment from urban settlements and industries has improved. As a result, nutrient inputs to the Danish marine waters have been reduced considerably. We report trends and delays in responses of various ecosystem components to these nutrient reductions. Nearly three decades after the first mitigation measures were implemented, all key ecosystem components (central chemical and biological variables) show evidence of a gradually healthier coastal ecosystem.

\section{Materials and Methods}

\section{Study Sites}

We examined 45 estuarine and coastal sites scattered across Denmark that have been regularly monitored as part of the Danish National Aquatic Monitoring and Assessment Program (DNAMAP). The majority of the study sites (29) are from the Kattegat and Belt Sea areas, i.e., the transition 
area between the brackish Baltic Sea and the saline North Sea and Skagerrak (Fig. 1). The five sites on the west coast of Denmark are influenced by north-flowing nutrient-rich waters from the southern North Sea. Two of these sites are located in the Wadden Sea, and two other sites represent lagoonal systems, where the exchange with the North Sea is controlled by sluices. A total of 10 sites are located in the Limfjorden complex, a shallow (mean depth $5.5 \mathrm{~m}$ ) strait connecting the North Sea to the west and the Kattegat to the east. Due to the dominating westerly winds, the transport of water is generally from the west to the east in this system. Finally, there is a station near Bornholm, an island in the southern Baltic Sea.

The study sites are located in a mid-latitude temperate climate zone with an average annual water temperature around $10^{\circ} \mathrm{C}$. Average salinities cover a broad span ranging from 7 to 31 among sites due to mixing of brackish Baltic Sea water with saline water from the Skagerrak and inputs of local freshwater. Danish estuarine and coastal ecosystems are for the most part shallow with residence times ranging from a few days up to several months (Conley et al. 2000). Tidal influence is small $(<0.5 \mathrm{~m})$, except for the Wadden Sea region (1.2$2.0 \mathrm{~m}$ ), and wind conditions generally govern water transports and vertical mixing in these shallow systems. Thus, stratification patterns vary greatly among sites and over time depending on water depths, density differences, and wind exposure.

Land use in the watersheds is dominated by agriculture ( $\sim 65 \%$; Windolf et al. 2012) with tiled soils in many areas, enhancing the loss of nutrients to estuaries and coastal regions. As a consequence, Danish estuaries and coastal waters are nutrient-rich ecosystems with a strong benthic-pelagic coupling due to their shallowness resulting in high biomass of benthic fauna in several of the estuaries (Conley et al. 2000; Josefson and Rasmussen 2000).

In connection with the APAE, a national aquatic monitoring program (DNAMAP) was established and a full program was running since 1989, to evaluate the efficiency of measures taken as well as to assess expected recovery of estuarine and coastal ecosystems. Data collection and analysis were undertaken by local authorities following common guidelines which have been continuously updated (http://bios.au.dk/ videnudveksling/til-myndigheder-og-saerligt-interesserede/ fagdatacentre/fdcmarintny/ta2011-2015/). Data from DNAM AP and regional monitoring programs previous to DNAMAP (1981-2013) were examined to describe changes in nutrient inputs from land resulting from nutrient management policies and the responses of estuarine and coastal systems to these changes. Water quality and density profiles (to express water column stratification) were measured at all 45 sites, whereas eelgrass, macroalgae, and benthic macrofauna (details given below) were monitored at 39, 36, and 43 of the sites, respectively. Whereas data series on physical-chemical conditions started in 1981, most of the biological data series started in $1989 / 1990$.

\section{Nutrient Inputs}

Inputs of total nitrogen and phosphorus (TN and TP, respectively) from land to coastal waters included both diffuse and point sources. TN and TP concentrations have been measured at 169 freshwater stations with a sampling frequency of 12-26 per year. TN and TP concentrations were determined by means of colorimetric methods (Danish Reference laboratory).

For the gauged catchments (57\% of total area), daily concentrations of TN and TP were estimated by linear interpolation between grab samples, and nutrient inputs were calculated by multiplying daily TN and TP concentrations with continuously measured freshwater discharges. For the ungauged catchment, freshwater discharge was provided from the 3Dhydrological model MIKE SHE adjusted for seasonal bias (Henriksen et al. 2003; Windolf et al. 2011). Gross outlets of TN and TP from diffuse sources were calculated by combining monthly modeled freshwater discharge and discharge weighted monthly concentrations of TN and TP from empirical models derived on measured data from $83(\mathrm{~N})$ and $24(\mathrm{P})$ gauging stations with no significant sewage outlets (Windolf et al. 2011; Andersen et al. 2005). Adding the outlets of nutrients with sewage in the ungauged catchments and subtracting estimated nutrient retention in streams and lakes then provided the total monthly nutrient load from ungauged catchments (Windolf et al. 2011, 2012).

Nutrient inputs from all point sources were also measured with a high frequency, which allowed for partitioning riverine nutrient inputs into diffuse and point sources. However, for the 1981-1989 period, TN and TP inputs from point sources were estimated as means for the entire period due to sparse data and diffuse nutrient inputs were estimated by extrapolation (scaling up) from five larger gauged catchments. Thus, estimated nutrient inputs from these earlier years were more uncertain than for the following years.

\section{Water Quality Measurements}

Sampling and measurements of TN, TP, chlorophyll $a$, the Secchi depth, and oxygen were carried out by different institutions and laboratories but followed a common set of technical guidelines and procedures. The 45 study sites (Fig. 1) were sampled 12-46 times per year. TN and TP concentrations were measured (by colorimetric methods), and chlorophyll $a$ was analyzed on filtered samples, extracted in acetone (19811984) or ethanol (1985 onwards) according to Strickland and Parsons (1972). Oxygen was measured from CTD-profiles and calibrated by Winkler-titration for each profile.

\section{Benthic Vegetation Monitoring}

Total macroalgal cover and the cumulative cover of the macroalgal community were estimated along depth gradients 
Fig. 1 Map of Denmark with coastal monitoring sites. The encircled areas represent sites situated at the Wadden Sea and at the Limfjord

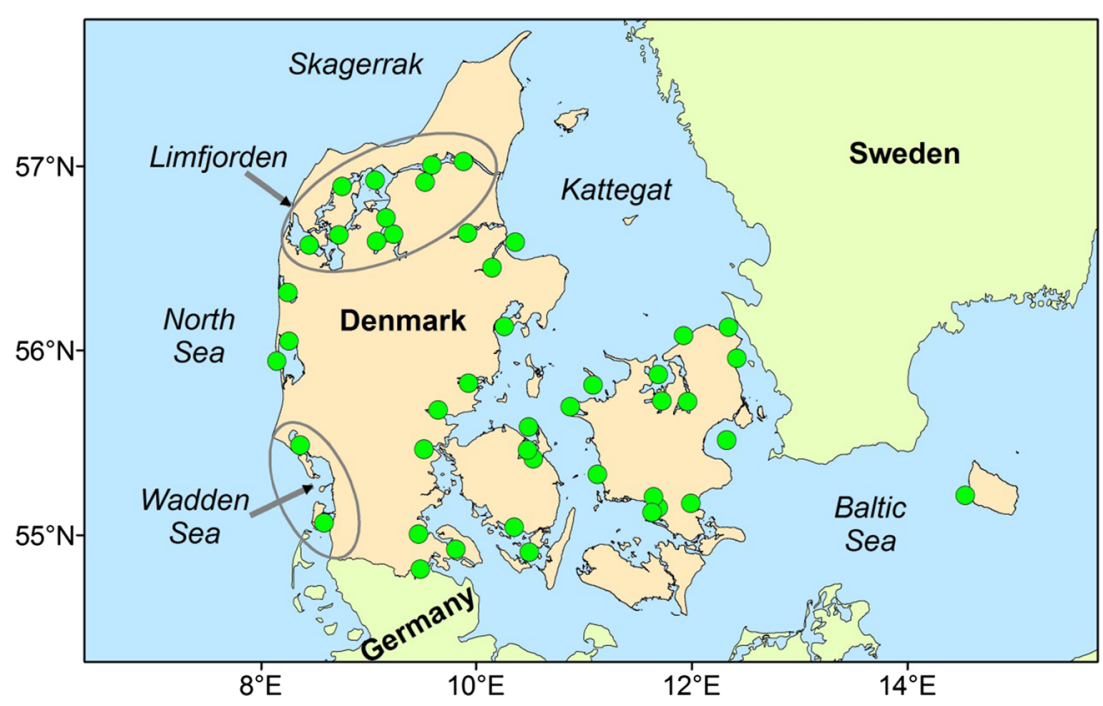

(sites) once every summer (May-September) by divers. The divers visually recorded the percent cover of the total erect macroalgal community and of individual erect algal species (i.e., excluding the crust-forming algae) relative to the hard, stable substratum within patches of $25 \mathrm{~m}^{2}$ seabed along depth gradients $(0-22 \mathrm{~m})$. The hard substratum primarily consists of stones and boulders, which are scattered on the seafloor as a result of postglacial erosion processes. Total algal cover was assessed as a percentage between 0 and $100 \%$ while cumulative cover was calculated by summing the cover percentages of all individual erect macroalgal species and exceeded $100 \%$ when the community formed multiple layers. Only data from depth ranges where physical disturbance was considered not to limit macroalgal cover were included (see specifications in Krause-Jensen et al. 2007b).

The depth extension of eelgrass (Zostera marina) meadows on soft/sandy seafloors was also estimated once annually between June and September along depth gradients (sites) extending from the shore to the deepest occurrence of eelgrass. The maximum depth limit (i.e., the depth of the deepest shoot) as well as the maximum depth of $10 \%$ eelgrass cover (main depth limit) were identified primarily by diver observations but in recent years increasingly by underwater video surveys after testing that this change of method did not significantly affect the results.

\section{Benthic Macrofauna Monitoring}

Macrofaunal biomass was monitored at 43 of the study sites with replication at grid areas having up to 50 sampling points. Sampling gears utilized were from the quantitative Van Veen Sampler, covering ca. $0.1 \mathrm{~m}^{2}$ bottom area and the smaller HAPS sampler covering $0.012-0.014 \mathrm{~m}^{2}$ bottom area. In principle, samples were taken in all months of the year, but most samples $(\sim 50 \%)$ were from May. Extraction of fauna followed the HELCOM guidelines (www.helcom.fi) using sieves with 1-mm mesh. Fauna was determined to the lowest possible taxon, typically species, enumerated and weighed. Biomass was recalculated from wet or dry weight (including shells or other calcified structures) and expressed as ash-free dry weight (gram AFDW $\mathrm{m}^{-2}$ ) as described by Josefson and Rasmussen (2000). Total biomass was divided into filter feeder biomass represented by bivalve biomass, and remaining biomass which in the following is referred to as depositfeeding biomass, since it was dominated by deposit-feeding species. Prior to the statistical analysis, the median of replicates within grid areas was computed to reduce the large spatial patchiness.

\section{Statistical Analyses}

For all monitoring components, data were heterogeneously distributed over time and space due to changes in the monitoring program over time and incomplete sampling due to weather conditions. Consequently, we employed a statistical method (for details, see Carstensen et al. 2006) that accounted for this heterogeneity by decomposing variations in data into spatial variation (between sites as well as monitoring stations/ transects nested within sites), seasonal variation (between months of sampling), and trend (between years of sampling). For macroalgae cover, the depth of the observations and the amount of hard substratum were also taken into account as covariates (details in Krause-Jensen et al. 2007a), and cover was modeled for a common water depth of $10 \mathrm{~m}$. The separation of sources of variation for the different components was carried out by means of generalized linear models (GLM), where log-transformations were applied to nutrient and chlorophyll $a$ concentrations, cumulative cover of macroalgae, and macrofauna biomass (variables having a pronounced rightskewed distribution and variation scaling with the mean). Logistic transformation was applied to total algal cover (variable constrained to $0-100 \%$ ) and no transformation was 
applied to the Secchi depth, oxygen concentration, and eelgrass depth limits. Trends for the various components were found as the marginal distributions of the yearly mean values back-transformed to their original scale using the inverse transformation (Carstensen et al. 2006, Krause-Jensen et al. 2007a, b). A 5-year moving average was employed to the yearly means for displaying a smooth trend to illustrate the evolving tendencies of the time series. Furthermore, decadal changes in the seasonal pattern were examined from the GLM by allowing the monthly means in the model to vary between decades.

We examined patterns of stratification over time by calculating density differences in water column profiles, using change in water density, $\Delta \sigma_{\mathrm{T}}=0.5$ as a threshold for separating between mixed and stratified conditions (Conley et al. 2007). The probability of observing stratified conditions during the summer period (June-September) was calculated with a GLM (as for nutrients above) for each year using stratified versus mixed conditions as a binomial variable, accounting for differences in sampling between sites and months. Similar to the other variables, the long-term tendency for the frequency of stratification was illustrated by running a 5-year moving average across the yearly probability of stratification.

Changes over time in the different ecosystem components were tested using a General Additive Model (GAM), which examines the significance of both linear trends and higher order trends by means of a spline function. The different time series were all analyzed for trends using annual means from the same years (1990-2013) in order to compare different responses to nutrient reductions that mainly took place from the onset of this period.

\section{Results and Discussion}

\section{Trends in Nutrient Inputs}

Land-based TN and TP inputs to Danish coastal waters have been reduced significantly during the last three decades (Fig. 2, Table 1). In the 1980s, TN inputs were 80-120, $000 \mathrm{t} \mathrm{N}_{\text {year }}{ }^{-1}\left(19-28 \mathrm{~kg} \mathrm{~N} \mathrm{ha}^{-1}\right.$ year $\left.^{-1}\right)$ with approximately $75 \%$ from diffuse and $25 \%$ from point sources. Improved sewage treatment in the 1990 s reduced nitrogen inputs from point sources by $\sim 75 \%$ to a current level of $5-$ $6000 \mathrm{t} \mathrm{TN} \mathrm{year}{ }^{-1}$. Nitrogen inputs from diffuse sources were more gradually reduced between 1990 and 2013, resulting in an overall reduction of $43 \%$ when adjusted for inter-annual variation in freshwater discharge (Fig. 2c).

At the agricultural field level, the nitrogen surplus was halved from levels $>400,000 \mathrm{t} \mathrm{N}_{\text {year }}{ }^{-1}$ in the early $1990 \mathrm{~s}$ (Windolf et al. 2012; Blicher-Mathiesen et al. 2014). This reduction was achieved through APAE requirements for manure storage capacity, rules for timing and application

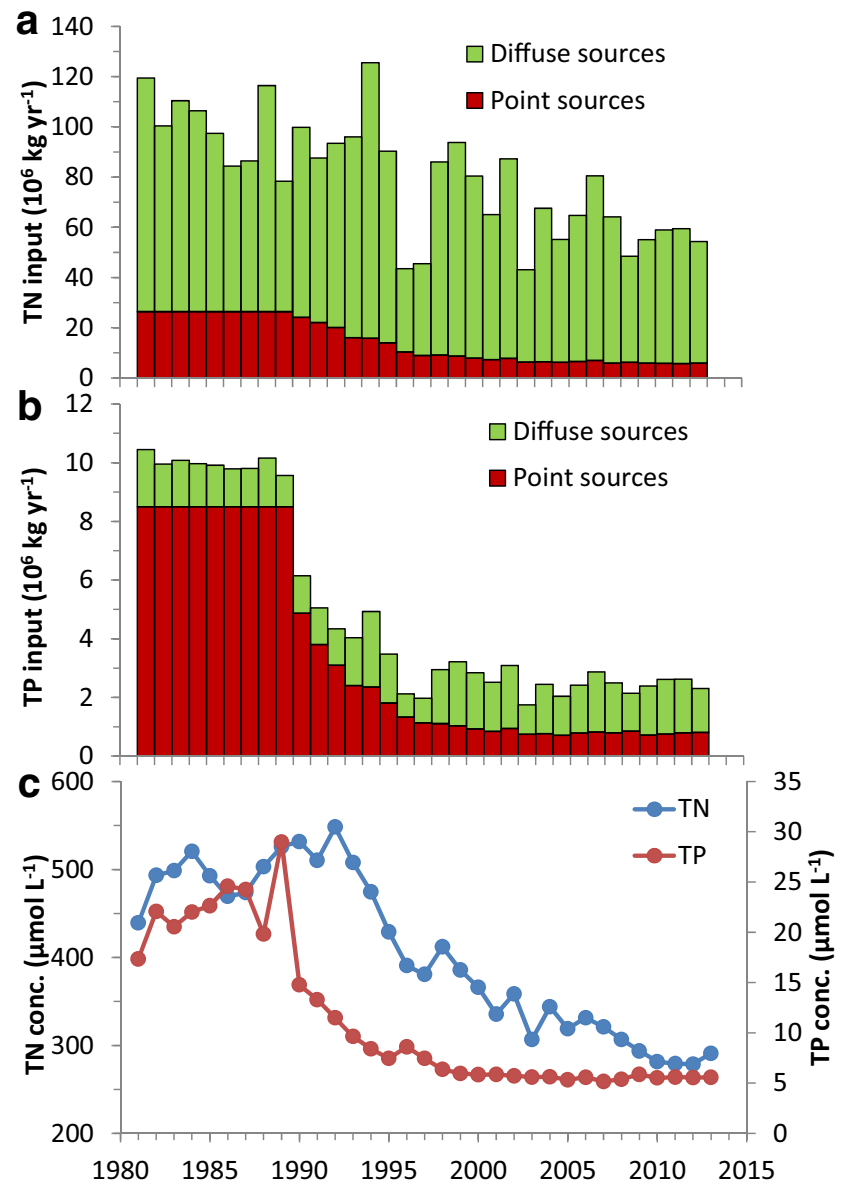

Fig. 2 Trends in nutrient inputs from diffuse and point sources for $\mathbf{a}$ total nitrogen $(T N)$, b total phosphorus TP, and $\mathbf{c}$ flow-weighted concentrations of TN and TP. Note different scaling in c. TN and TP inputs during 19811989 were estimated as means for the entire period due to sparse data, and diffuse nutrient inputs were estimated by extrapolation (scaling up) from five larger gauge catchments

technique of manure, maximum limits to the amount of $\mathrm{N}$ which may be applied to different crops, and wetland restoration increasing the $\mathrm{N}$ retention in surface waters. In most Danish catchments, the response times from measures to effects on stream concentrations are fast, although a few catchments show delayed responses (several years to decades), because of dominating flow through deep groundwater (Windolf et al. 2012).

TP inputs from point sources were significantly reduced by $>90 \%$ since the mid-1980s due to improved sewage treatment (Fig. 2), whereas inputs from diffuse sources have not been reduced overall; although some indications of minor reductions in diffuse $\mathrm{P}$ pollution were observed in 14 out of 31 minor streams draining farmed land (Windolf et al. 2011). Although the reduction in both TN and TP inputs was substantial, the present annual inputs $\left(55,000 \mathrm{t} \mathrm{N}^{\mathrm{N}}\right.$ year $^{-1}$, $2400 \mathrm{t} \mathrm{P} \mathrm{year}^{-1}$ ) are still markedly higher that the baseline loads of TN and TP estimated at 13,000 t N year ${ }^{-1}$ and $730 \mathrm{t} \mathrm{P}^{\mathrm{P}} \mathrm{yer}^{-1}$ (Kronvang et al., in press). 
Table 1 Trends in response to nutrient management plans $(1990-2013)$

\begin{tabular}{llrr}
\hline Variable & Slope linear trend & $p$ (linear) & $p$ (spline) \\
\hline TN input from land & $-1.8910^{6} \mathrm{~kg} \mathrm{year}^{-1}$ & $\mathbf{0 . 0 0 1 6}$ & 0.5372 \\
TP input from land & $-0.1120^{6} \mathrm{~kg} \mathrm{year}^{-1}$ & $<\mathbf{0 . 0 0 0 1}$ & $<\mathbf{0 . 0 0 0 1}$ \\
TN concentration & $-1.09 \mu \mathrm{mol} \mathrm{L}^{-1} \mathrm{year}^{-1}$ & $<\mathbf{0 0 0 1}$ & 0.2377 \\
TP concentration & $-0.028 \mu \mathrm{mol} \mathrm{L}^{-1} \mathrm{year}^{-1}$ & $<\mathbf{0 . 0 0 0 1}$ & $<\mathbf{0 . 0 0 0 1}$ \\
Chlorophyll $a$ & $-0.057 \mathrm{~mol} \mathrm{~L}^{-1} \mathrm{year}^{-1}$ & $<\mathbf{0 . 0 0 0 1}$ & 0.1341 \\
Secchi depth & $0.001 \mathrm{~m} \mathrm{year}^{-1}$ & 0.9126 & 0.1206 \\
Oxygen concentration & $-0.009 \mathrm{mg} \mathrm{L}^{-1}$ year $^{-1}$ & 0.5433 & 0.7228 \\
Macroalgae total cover & $0.69 \%$ year $^{-1}$ & $\mathbf{0 . 0 0 0 7}$ & 0.6722 \\
Macroalgae cumulative cover & $1.49 \%$ year $^{-1}$ & $\mathbf{0 . 0 1 8 2}$ & 0.4429 \\
Eelgrass maximum depth & $-0.006 \mathrm{~m} \mathrm{year}^{-1}$ & 0.1172 & $\mathbf{0 . 0 0 8 0}$ \\
Eelgrass main depth & $-0.006 \mathrm{~m} \mathrm{year}^{-1}$ & 0.1657 & $\mathbf{0 . 0 0 4 1}$ \\
Biomass macrofauna & $-0.185 \mathrm{~g} \mathrm{AFDW} \mathrm{m}^{-2}$ year $^{-1}$ & $\mathbf{0 . 0 0 8 5}$ & 0.2145 \\
Biomass deposit feeders & $0.089 \mathrm{~g} \mathrm{AFDW} \mathrm{m}^{-2}$ year $^{-1}$ & $\mathbf{0 . 0 0 2 0}$ & $\mathbf{0 . 0 1 4 1}$ \\
Biomass filter feeders & $-0.307 \mathrm{~g} \mathrm{AFDW} \mathrm{m}^{-2}$ year $^{-1}$ & $<\mathbf{0 . 0 0 0 1}$ & 0.0662 \\
\hline
\end{tabular}

For each ecosystem component, the linear trend and significance as well as the significance of higher order trend (spline) is listed. Significant trends $(p<0.05)$ are highlighted in bold

\section{Trends in Nutrient Concentrations}

TN concentrations in Danish estuaries and coastal waters largely followed the trends in nitrogen inputs, decreasing from an almost constant level around $50 \mu \mathrm{mol} \mathrm{L}{ }^{-1}$ before 1995 to a present level of about $25 \mu \mathrm{mol} \mathrm{L}{ }^{-1}$ in 2013 (Fig. 3a). The decreasing tendencies were observed throughout all months of the year, albeit reductions were largest in winter and spring (Fig. 3b). Highest TN levels were measured in February decreasing from a mean of $82 \mu \mathrm{mol} \mathrm{L}^{-1}$ in the 1980 s to $44 \mu \mathrm{mol} \mathrm{L}^{-1}$ in the most recent decade. Similarly, TN levels from May to October dropped from around 40 to $20 \mu \mathrm{mol} \mathrm{L}^{-1}$ over this time period. The decrease in TN concentrations was consistent with reduction in nitrogen inputs from APAEs targeting diffuse sources.

TP concentrations also followed the trends in phosphorus inputs, decreasing from an almost constant level around $2.2 \mu \mathrm{mol} \mathrm{L}{ }^{-1}$ before 1990 and with a rapid decline over the next 6-8 years followed by a more modest decrease to the present level of around $1 \mu \mathrm{mol} \mathrm{L}{ }^{-1}$ (Fig. 3c). The seasonal trends had a pronounced higher TP level during late summer (July to September) in the first decade $\left(2.6 \mu \mathrm{mol} \mathrm{TP} \mathrm{L}{ }^{-1}\right.$ during 1981-1989) but this was gradually reduced by $50 \%$ in the following decades. Phosphorus inputs in the 1980s were dominated by point sources that display a weak seasonal pattern. Consequently, the TP increase in late summer was mainly driven by sediment releases. Over the study period, the dominant phosphorus input from land changed from point to diffuse sources (Fig. 2), leading to relatively larger inputs over winter. Thus, the increased TP concentration during late summer in recent years suggests that there is still a considerable internal input of phosphorus despite that this source has diminished over time.
TN and TP concentrations displayed different trends, mirroring the reduction patterns in the land-based inputs (Fig. 2, Table 1). The first APAE gave improved sewage treatment, which had a large effect on phosphorus concentrations, whereas the following APAEs targeted mainly nitrogen losses from agriculture, and were implemented ca 5 years later and over longer periods. These out-of-phase reductions changed $\mathrm{N} / \mathrm{P}$ ratios in estuaries and coastal areas, shifting towards stronger potential phosphorus limitation in the 1990s and increasing potential nitrogen limitation thereafter.

\section{Trends in Phytoplankton}

Annually, mean chlorophyll $a$ concentrations showed a maximum at $7 \mu \mathrm{g} \mathrm{L}^{-1}$ in 1985 with a steady decrease thereafter to the present level of $\sim 2.5 \mu \mathrm{g} \mathrm{L}^{-1}$ (Fig. 4a). The seasonal chlorophyll $a$ pattern in the 1980s was almost unimodal (Fig. 4b), mimicking seasonal changes in solar irradiance and temperature. This unimodal shape of the chlorophyll $a$ seasonal pattern was probably maintained by a continuous and high supply of nutrients from point sources throughout all seasons during the 1980s, alternating with periods with nutrient limitations. Inputs from diffuse sources are relatively low during the productive season. This suggests that phytoplankton growth was not strongly limited by the availability of nutrients in these years compared to the shapes for the other decades. Moreover, it is unlikely that phytoplankton growth was light limited during the productive season from March to October in these shallow microtidal estuaries and coastal waters, where the Secchi depths (see below) largely match water depths (71 \% are less than $4 \mathrm{~m}$ deep; Conley et al. 2000). In the 1990s and later, a more characteristic bimodal seasonal pattern emerged with a pronounced spring bloom, as expected in 
Fig. 3 Trends in coastal nutrient concentrations. Annual mean concentrations of TN (a) and TP (c) are shown with the $95 \%$ confidence interval and a 5-year moving average of the means. Changes in the seasonal pattern (monthly means) over different decades are displayed for TN (b) and TP (d). A 5-year moving average is shown with a gray line in $\mathbf{a}$ and $\mathbf{c}$

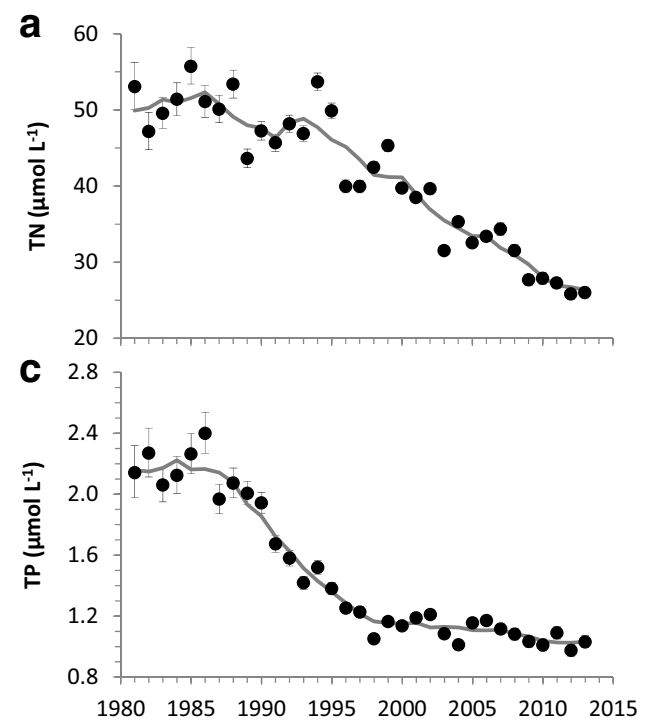

nutrient-limited mid-latitude coastal ecosystems (Wasmund et al. 1998), and higher production in late summer and early autumn, when regenerated nutrients were available. In coastal ecosystems, the spring bloom is mostly fueled by new production, utilizing nutrients accumulated during the lightlimited winter period, whereas production in the following months is increasingly based on regenerated nutrients (Carstensen et al. 2003).

Changes in the grazing pressure exerted by filter feeders can induce large changes in the phytoplankton community (Cloern et al. 2007; Petersen et al. 2008), but such changes would be most prominent in the warmer summer months and not in April-May, where the largest change in chlorophyll $a$ were experienced (Fig. 4b).

Many Danish estuaries display phosphorus limitation in spring switching to nitrogen limitation in early summer (Conley et al. 2000). Upgrading the sewage treatment plants strongly reduced phosphorus inputs to estuaries and coastal waters in Denmark, increasing the potential phosphorus limitation during spring. The effect of phosphorus limitation in spring is further supported by the peak of the spring bloom,

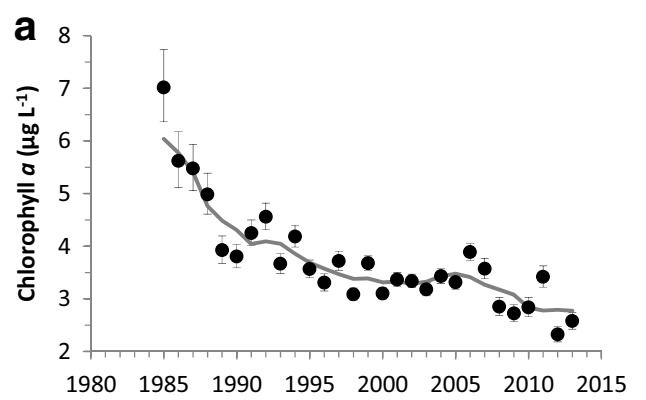

Fig. 4 Trends in chlorophyll a concentrations. a Annual mean concentrations are shown with the $95 \%$ confidence interval, and a 5year moving average of the means displayed. The results from the first 4 years (1981-1984) have been omitted in the 5-year moving average which dropped from the 1980s and remained constant afterwards; consistent with the changes in TP concentrations (Fig. 3c). On the other hand, the continuous decline in chlorophyll $a$ from the mid-1990s until present was mainly related to decreasing nitrogen levels. This is observed by decreasing chlorophyll $a$ concentrations in May-October, when phytoplankton growth is mainly nitrogen limited. Decreasing N/P ratios, as experienced since the 1990 s, will extend the summer nitrogen limitation further into the spring period. Our results demonstrate that controlling both nitrogen and phosphorus is important for reducing the effects of eutrophication (Conley et al. 2009).

\section{Trends in Water Clarity}

Light attenuation and thus water clarity was quantified as the Secchi depth (Fig. 5). The Secchi depth increased from about $4.2 \mathrm{~m}$ in early 1980 s to $5.1 \mathrm{~m}$ in 2013 ; however, the uncertainty of the mean estimates was larger in the beginning of the period due to fewer stations and lower sampling frequency. The most pronounced increase in the Secchi depth from the

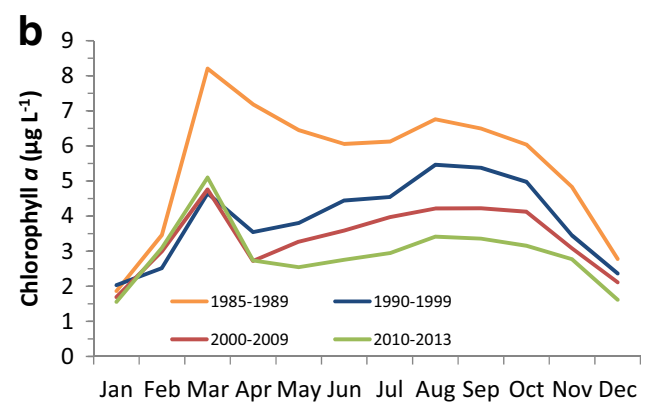

because of different extraction solvents, see "Materials and Methods". b Changes in the seasonal pattern in chlorophyll $a$ (monthly means) over different periods. A 5-year moving average is shown with a gray line in a 

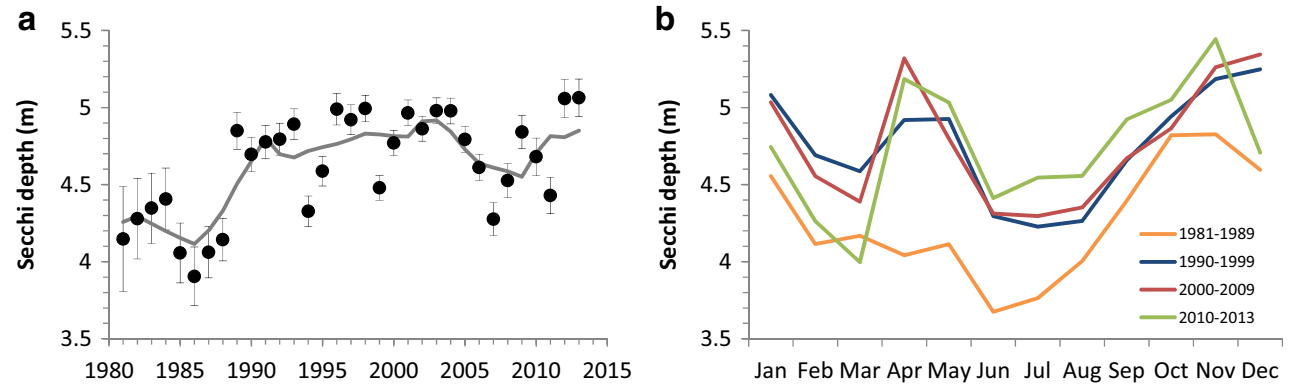

Fig. 5 Trends in the Secchi depth. Annual means (a) are shown with the $95 \%$ confidence interval and a 5 -year moving average of the means. b Changes in the seasonal pattern in the Secchi depth (monthly means) over different periods. A 5-year moving average is shown with a gray line in a

1980s to the 1990s was observed in April-May, consistent with decreasing chlorophyll $a$ concentrations (Fig. 4b). Both observations were in agreement with low and limiting concentrations of inorganic phosphorus during the spring, and previous results have demonstrated significant correlations between P-loading, primary production, chlorophyll concentration, and water clarity (Timmermann et al. 2014). Overall, there was a reasonable agreement between the trends of decreasing chlorophyll and increasing the Secchi depth. However, this does not imply that chlorophyll was responsible for the observed changes in light attenuation. In fact, results have shown that chlorophyll accounted for a small fraction, often less than $20 \%$ (Pedersen et al. 2014), of light absorption and attenuation. The opposite trends for chlorophyll and the Secchi depth were therefore most likely due to a decrease in productivity and organic matter in the systems.

Although recent improvements in the Secchi depth have been modest, the use of the Secchi depth as a measure of water clarity might actually overestimate the improvement in light levels at depth. Pedersen et al. (2014) showed that in the Roskilde Fjord (one of the study sites), there has been a systematic increase in the product of the light attenuation coefficient and the Secchi depth $\left(\mathrm{Kd} \times \mathrm{Z}_{\mathrm{SD}}\right)$, which reflects the percentage of surface light at the Secchi depth. In the Roskilde Fjord, this dimensionless product increased from 1.8 to 2.2 between 1985 and 2008-09, implying that less light was available at the Secchi depth during 2008/9 as compared to 1985 . This change reflected a decrease in scattering due to lower concentrations of particles (Pedersen et al. 2014). The implication of this relative shift in light attenuation between scattering and absorbance is that benthic flora is likely to change less than improvements in the Secchi depth may predict. A large decrease in particulate organic matter following nutrient reductions was also reported in Limfjorden, whereas inorganic particles increased most likely due to loss of eelgrass meadows and benthic filter feeders (Carstensen et al. 2014). These studies support that nutrient reduction in general improves water clarity, but these trends can be confounded with changes in other light-attenuating substances. For the spring period, however, there was a direct and immediate response between water clarity and P-loading.

\section{Trends in Bottom Water Oxygen}

Despite significant reductions in nutrient inputs, there were no significant changes in summer oxygen concentration in waters below the pycnocline (Fig. 6a). Actually, the frequency of oxygen depletion increased during the 1990s (Fig. 6b), most likely due to more frequent stratification of the water column during this period (Fig. 6c). Stronger stratification may be explained by an overall decrease in the summer wind speed, and increasing bottom water temperatures further stimulates oxygen consumption and oxygen depletion (Conley et al. 2007). This suggests that the expected improvement in oxygen concentration from nutrient reductions may have been counteracted by changing climate. The potential effect of wind and temperature can be exemplified by relatively high oxygen concentration in the windy (i.e., low frequency of stratification) and cold summer of 1993, even though large nitrogen inputs may have stimulated production and subsequently oxygen consumption.

Most of the shallow estuaries and coastal areas in Denmark are intermittently stratified (Conley et al. 2000), and during periods of stratification oxygen in bottom waters is gradually utilized due to the high respiration rates in the sediments during summer. If the bottom layer is thin, the oxygen pool may deplete within a few days. The lower average wind speed observed since 1990 (Conley et al. 2007) not only increased the frequency of stratification, but most likely also increased the periods with stratified conditions. However, the mean oxygen concentration (June-September) remained stable around $4 \mathrm{mg} \mathrm{L}^{-1}$ during the study period despite an expected longer duration of stratified conditions, which suggests that oxygen consumption may have decreased since 1990.

\section{Trends in Benthic Flora}

The relatively long life-span of benthic macroalgae and seagrasses implies that they can integrate and reflect the ecological quality over multiple years. Light energy is the main regulator of the abundance of vegetation in deeper waters, determining the depth extension of the plants (Markager and Sand-Jensen 1992). Hence, macroalgal cover in deeper water 


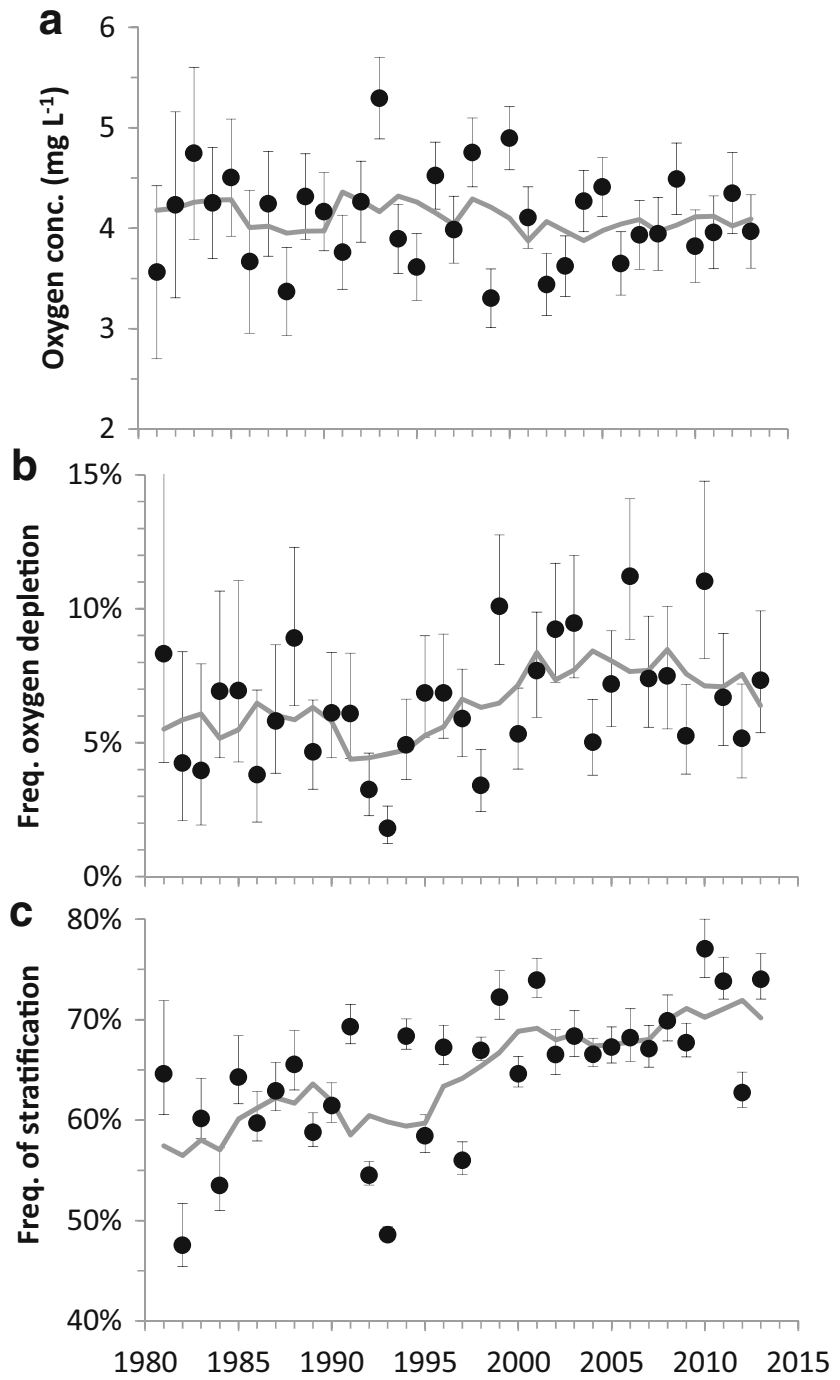

Fig. 6 Trends in mean annual values of a bottom water oxygen concentration during stratification $\left(\Delta \sigma_{\mathrm{T}}>0.5\right)$ for June-September, b frequency of oxygen depletion $(<4 \mathrm{mg} / \mathrm{L})$ for June-September, and c frequency of stratification $\left(\Delta \sigma_{\mathrm{T}}>0.5\right)$ for June-September. Error bars show the $95 \%$ confidence intervals. The gray lines show a 5 -year moving average

and the depth limit of eelgrass depends on light attenuation in the water column as well as on the abundance of epiphytes and drifting algae, which is generally favored by high nutrient supply (Duarte 1995; Cloern 2001; Kemp et al. 2005a, b).

Macroalgal vegetation is typically dense and multilayered in moderately exposed areas where incident light levels exceed $10-15 \%$ of surface irradiance and gradually thinner towards the boundary of the photic zone. On average for the studied ecosystems, total macroalgal cover at $10 \mathrm{~m}$ depth ranged between 54 and $86 \%$ and cumulative cover between 69 and $148 \%$ with minimum levels recorded in 1994 and 2004 and maximum levels in 2006 (Fig. 7a, b). Macroalgal cover exhibited an overall increase from 1990 to 2013 despite marked year-to-year variation; total cover increased by $0.69 \%$ per year and cumulative cover by $1.49 \%$ per year over this period (Table 1). This increase in algal cover mirrored the observed decline in TN and chlorophyll $a$ concentrations (Figs. 3 and 4) and occurred even though the Secchi depths solely increased during the most recent years and not during the period 1990-2013 as a whole (Fig. 5, Table 1). Probably, macroalgal cover was favored by reduced cover of drifting macroalgae (Rasmussen et al. 2014) and epiphytes during this period. The positive coupling between macroalgal cover and total $\mathrm{N}$ concentration matches findings from earlier studies in the region (Krause-Jensen et al. 2007a, b).

The shallow and relatively protected Danish coastal waters with predominantly soft and sandy seafloors constitute a key habitat area for eelgrass despite marked declines in area distribution and depth extension over the past century (Boström et al. 2014). On average, eelgrass meadows occur from the shore to maximum water depths of 3-4 $\mathrm{m}$ with the deepest shoots generally extending $0.3-0.4 \mathrm{~m}$ deeper (Fig. 7c) than the edge of the meadows as defined by $10 \%$ cover (Fig. $7 \mathrm{~d}$ ). The average annual depth extension was associated with a large standard error reflecting a marked variation among coastal areas with eelgrass not extending deeper than $1.6 \mathrm{~m}$ in the most turbid inner estuaries and growing deeper than $7 \mathrm{~m}$ in the clearest outer estuaries and open coastal areas. Across the period 1990-2013, eelgrass depth limits showed no significant trend (Table 1). However, while the meadows tended to gradually retract to shallower waters from 1989 until 2007/2008, they have extended to increasingly deeper waters over the past 5 years and in 2013 they were very close to the maximum extension for the entire monitoring period. The light regime is the most important factor regulating eelgrass depth limits (Stæhr and Borum 2011), and this positive development is likely a consequence of the increase in water clarity in recent years (Fig. 5), possibly also stimulated by reduced cover of drifting macroalgae in the meadows (Rasmussen et al. 2014).

\section{Trends in Benthic Macrofauna}

Inter-annual changes in benthic macrofauna biomass over the period 1989-2013 were substantial (Fig. 8), displaying significant decreasing trends for the filter feeders and total macrofauna community and significant increasing trend for deposit feeders (Table 1). Total macrofauna biomass decreased gradually from around 14 to $10 \mathrm{AFDW} \mathrm{m}{ }^{-2}$ (Fig. 8a). Filter feeders (mainly Mytilus edulis, Mya arenaria, and Cardium spp.) dominated the total macrofauna biomass in the 1990s, but the biomass of this group decreased by factor of 3 , from about $9 \mathrm{~g} \mathrm{AFDW} \mathrm{m}^{-2}$ in 1989 to approximately $3 \mathrm{~g} \mathrm{AFDW} \mathrm{m}^{-2}$ in recent years (Fig. 8b), whereas the biomass of deposit feeders (mainly polychaetes and Hydrobia spp.) almost doubled from the 1990s to the most recent decades (Fig. 8c).

The observed trends in macrofauna biomass during the last two decades are results of decreasing nutrient inputs (Fig. 2) and lower phytoplankton biomass (Fig. 4). Lower nutrient 
Fig. 7 Trends of benthic plant cover. a macroalgae total cover, $\mathbf{b}$ cumulative macroalgal cover, $\mathbf{c}$ eelgrass maximum depth limits, and $\mathbf{d}$ main depth limits of eelgrass. Annual means are shown with the $95 \%$ confidence interval. Gray lines are a 5-year moving average of the means
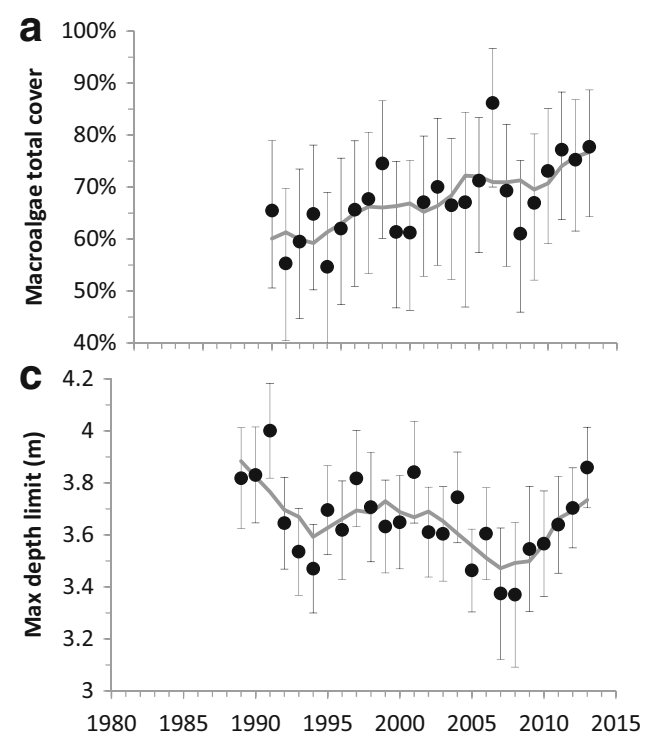

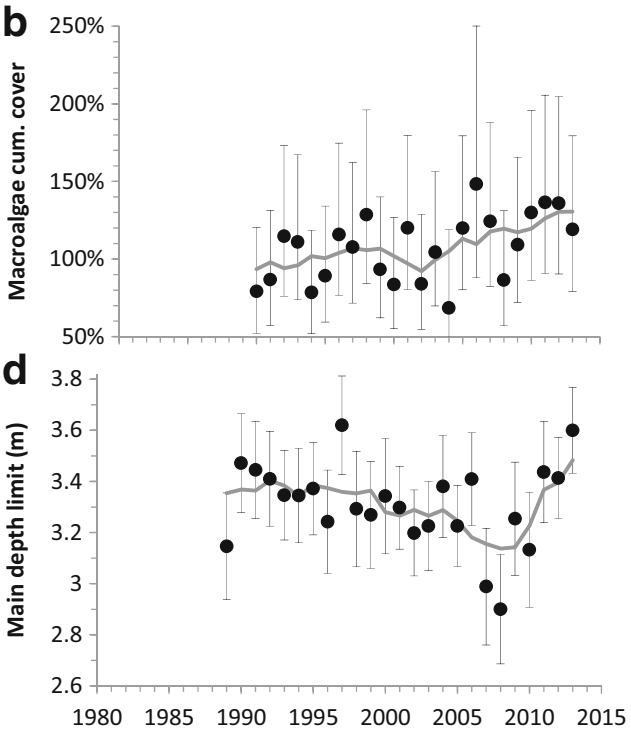

inputs reduces primary production and hence food supply for benthos (both filter feeders and deposit feeders), with a lower standing stock of macrofauna as a consequence (Pearson and Rosenberg 1978; Josefson and Rasmussen 2000; Nixon and Buckley 2002). Hypoxic conditions also have a large impact on macrofauna biomass, but oxygen concentrations remained rather stable over the study period (Fig. 6a). Mussel dredging may also have impacted the macrofauna community, but mussels are harvested only from a subset of the coastal monitoring sites and decreasing trends were also observed in areas not exposed to mussel dredging (data not shown). Therefore, it is most likely that the decreasing macrofauna biomass resulted from nutrient reductions.

However, the shift between decreasing biomass of filter feeders and increasing biomass of deposit feeders is intriguing. Filter feeders are decoupled from their food source during periods of stratification, and the large decline in filter feeder biomass is probably linked to a combination of lower phytoplankton biomass (Fig. 4) and increasing stratification in summer (Fig. 6c). The reduced filter effect implies that more particles are kept in suspension in the water column, which affects light conditions negatively. This could explain why the Secchi depths did not respond more clearly to lower nutrient inputs and phytoplankton biomass (Figs. 2 and 4). Particles in the water column eventually reach the seafloor, increasingly by sedimentation over time, delivering food to deposit feeders. Thus, deposit feeders have benefitted from the increasing stratification, despite an overall decrease of food availability.

\section{Synthesis}

Our results document long-term trends in physicochemical and biological ecosystem components in Danish estuaries and coastal waters during a 25 -year period of reductions in nutrient inputs. Overall, the ecosystems exhibited trends of recovery towards better environmental status, and pathways of recovery differed among ecosystem components (Figs. 9 and 10).

\section{Direct Effect of Nutrient Reductions}

The first recovery pathway was a direct response of reduced nutrient concentrations (Fig. 3a, c), mimicking the reduction patterns of the inputs (Fig. 2a, b). TP inputs dropped substantially during the $1990 \mathrm{~s}$, as a response to the improvements in the urban waste water treatment plants and industries with separate discharge, but the relative reductions in TP concentrations were not as large as the reductions of inputs from land (Fig. 9a). This difference in trends during the 1990s suggests that other inputs of phosphorus became increasingly important over time, i.e., imports from the open waters and releases of iron-bound phosphate from the sediments during periods of low oxygen concentrations (Conley 2000; Carstensen et al. 2014). Since 2000, however, TP concentrations in the open coastal waters and, thus, the import of phosphorus from this source have remained relatively constant (Hansen 2012). However, TP concentrations continued to decrease after 2000 , particularly during the summer-autumn period (Fig. 3d), suggesting a continued gradual depletion of the internal phosphorus pool. This depletion process may continue for some time still, but the small difference in the seasonal patterns in water column concentrations in the last two decades (Fig. 3d) indicates that the internal inputs are also stabilizing.

$\mathrm{TN}$ inputs from land and TN concentrations in estuarine and coastal waters decreased almost in parallel, although the trends suggest a delay in the response of $\mathrm{TN}$ concentrations from the beginning of the period until 2009 (Fig. 9a). Moreover, whereas the TN inputs have stabilized over the last 5 years (Fig. 2a), 


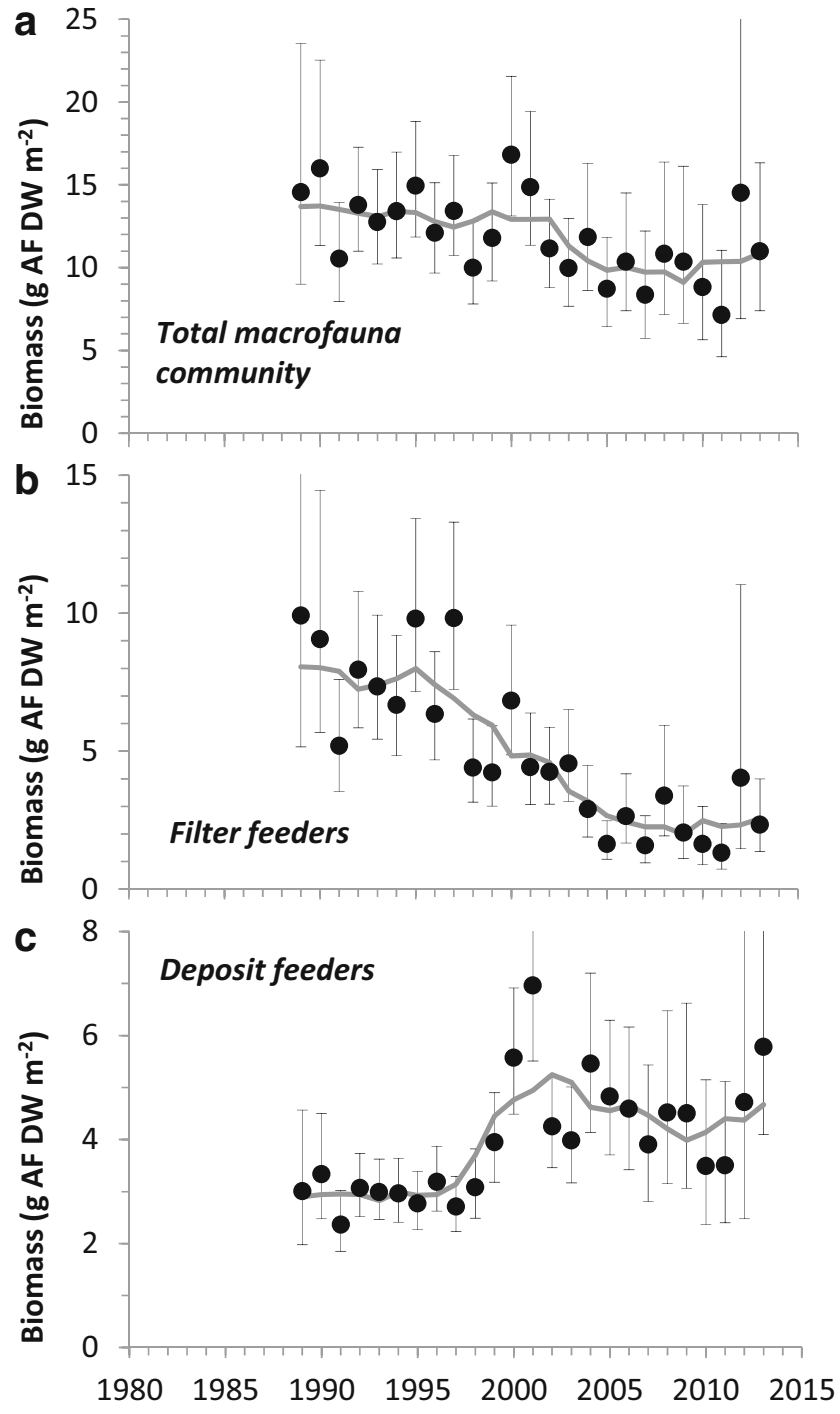

Fig. 8 Trends of benthic macrofauna. Annual means of a total biomass, b biomass of filter feeders, and $\mathbf{c}$ other benthic fauna (mainly deposit feeders. Error bars are $95 \%$ confidence intervals and each mean is based on a varying number of samples taken either in a sampling grid or at point stations. Gray lines are a 5-year moving average of the means

TN concentrations continue to decrease (Fig. 3a), underlining the delay in response. This delay is most likely due to continued reduction in internal $\mathrm{N}$-inputs from sediments (ammonium and nitrate) in combination with decreasing TN inputs from the open waters which show continued reduction in TN concentrations (Hansen 2012). Lower concentrations of particulate nitrogen in the water column, as reflected by the trends in TN and chlorophyll $a$ concentrations (Figs. $3 \mathrm{a}$ and $4 \mathrm{a}$ ) contribute to reducing the nitrogen pool in the sediments.

\section{Combined Effect of Nutrient Reduction and Increasing Stratification}

The second recovery pathway describes the combined effect of nutrient reductions and increasing stratification.
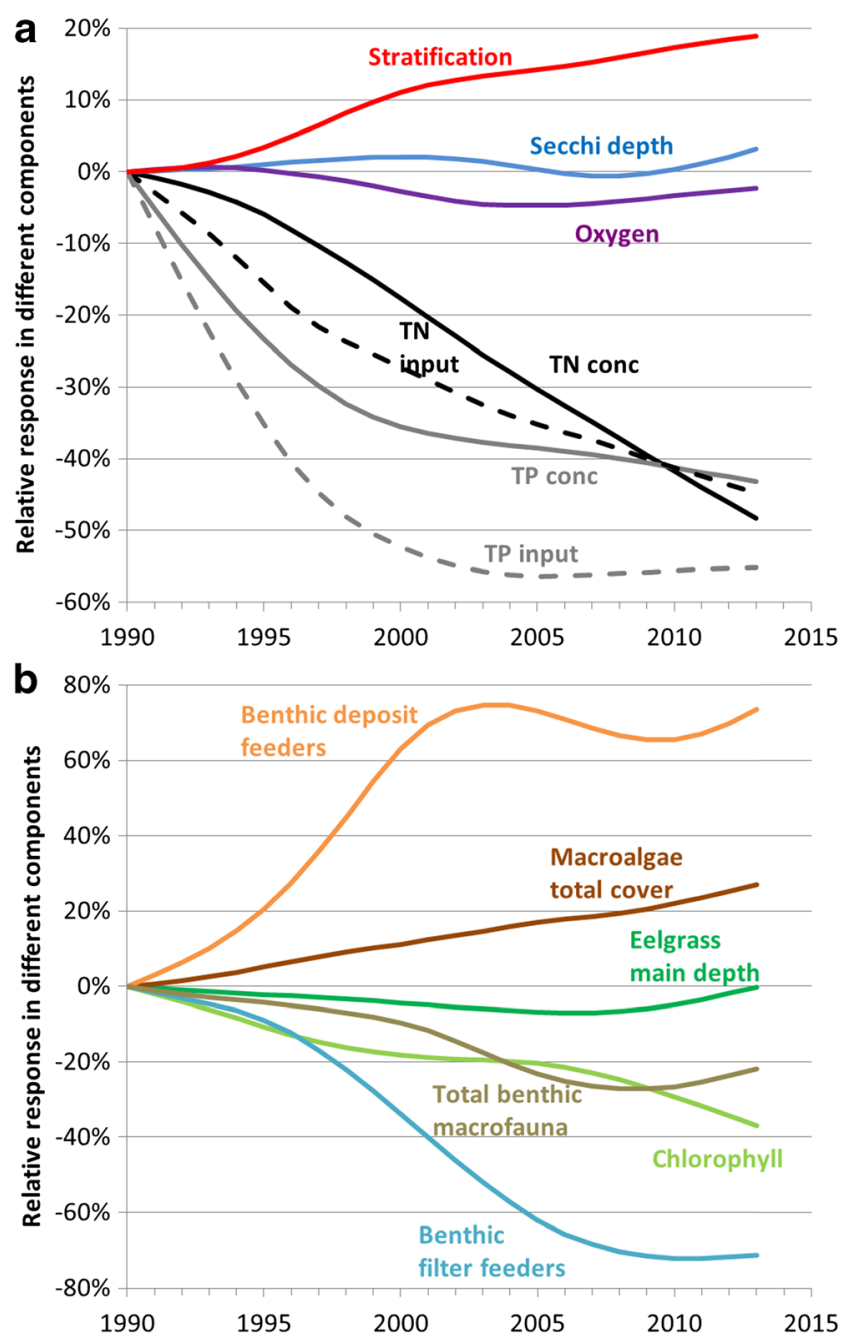

Fig. 9 Relative responses of a physical and chemical conditions and $\mathbf{b}$ biological components in Danish coastal waters (1990-2013). Curves are derived from the smooth GAM (General Additive Model) trends applied to the annual means in Figs. 2-8 using 1990 as reference for all components

Chlorophyll $a$ concentrations decreased following reductions in nutrient concentrations, but the decline was relatively smaller than for nutrient concentrations (Fig. 9a). This may be due to increased stratification during the same period. When the water column is mixed, filter feeders possess the capacity to filter the entire water column up to several times per day, removing a large fraction of particles ranging from nanometer to millimeter scale (Petersen 2004; Riisgård et al. 1995). However, increasing stratification acts to decouple filter feeders from phytoplankton and thereby results in reduced benthic grazing and, consequently, higher chlorophyll $a$ concentrations. On the other hand, it is also possible that the increasing stratification caused a shift from benthic to pelagic grazers such as ciliates and copepods.

Increased stratification of the water column reduces the supply of oxygen from the productive surface layers to bottom layers and hence acts to reduce oxygen concentrations below 


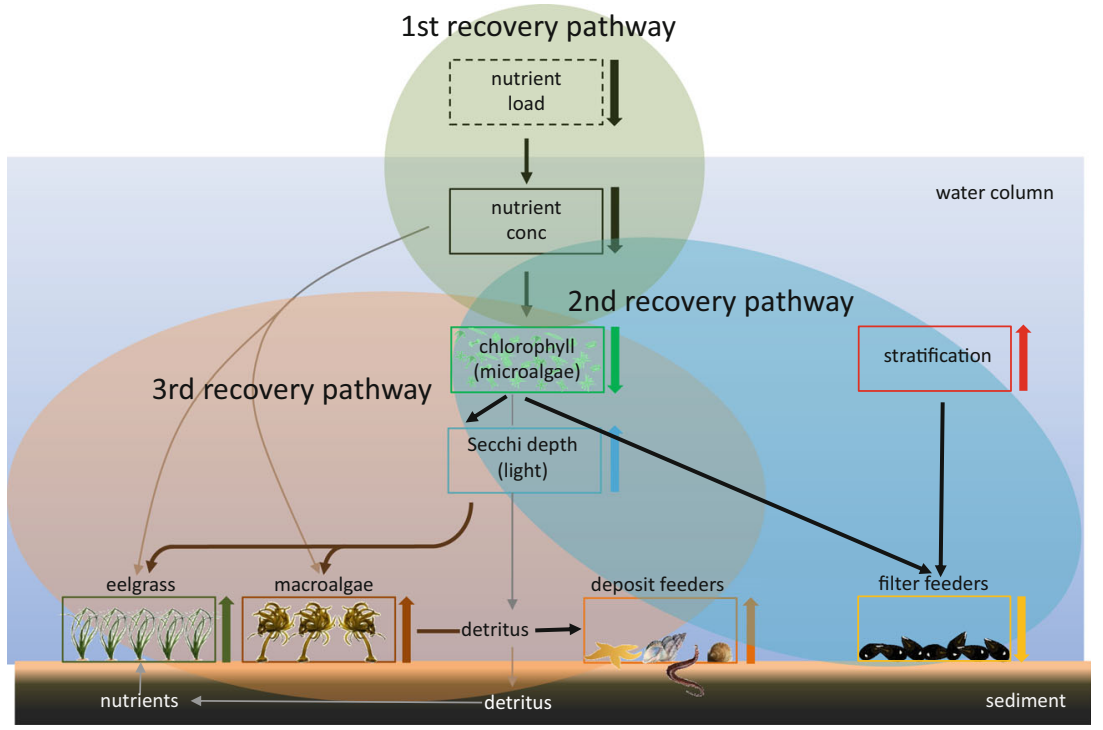

Fig. 10 Simplified sketch showing the interpretation of how reduced nutrient loads to the marine environment affect the measured parameters shown as boxes (same colors used as in Fig. 9a, b). Primary processes and functions shown as black thick arrows between boxes and additional key couplings are shown by gray thin arrows. Chemical/ physical parameters comprise nutrient load to the water body (stipulated black box), water column nutrient concentrations (black box), and the Secchi depth (i.e., light penetration; blue box). Biological parameters

the pycnocline. Warming amplifies this effect by stimulating respiration rates and reducing the solubility - and hence the concentration of oxygen (Rabalais et al. 2009). However, as mean oxygen concentrations during summer remained stable over the study period, the negative effects of increased stratification and warming must have been counter-balanced by declining oxygen demands over the study period. The declining trends in chlorophyll concentrations (Fig. 4) reflect declining phytoplankton primary production which likely resulted in reduced oxygen demand from degradation of organic material (Conley et al. 2007). Decreasing total macrofauna biomass (Fig. 8) also suggests that less organic material was produced in the water column over the study period.

We further hypothesize that increased stratification caused the change in composition of the benthic macrofauna from dominance of filter feeders towards dominance of deposit feeders (Fig. 8), with possible ramifications for sediment stability (see below).

\section{Feedback Effects from Sediment Resuspension}

The third recovery pathway described feedback mechanisms acting through the sediments. Surprisingly, the Secchi depth did not improve after 1990 despite decreases in chlorophyll $a$ concentrations (Fig. 9, Table 1). Consequently, the concentration of other light-attenuating substances must have increased. Carstensen et al. (2013) reported unaltered levels of total organic carbon (TOC) in the water column in the Skive Fjord comprise chlorophyll (i.e., microalgae; green box), eelgrass (olive box), macroalgae (brown box), deposit feeders (orange box), and filter feeders (yellow box). Downward and upward solid arrows show decreasing and increasing values, respectively, resulting from the reduced nutrient load. Water column stratification (red box), uncoupled from nutrient load has increased during the reporting period as a result of lesser wind and higher water temperatures

(one of the sites used in the overall analysis) despite almost $50 \%$ reductions in nutrient levels and increasing levels of inorganic suspended solids (mostly silt and clay particles). TOC is mostly dissolved material originating from autochthonous sources (Carstensen et al. 2013). Increasing trends in TOC and inorganic suspended solids can be linked to three mechanisms: (1) more particles remain suspended in the water column due to decreasing filtration from benthic filter feeders, (2) enhanced releases of dissolved organic material, and (3) enhanced sediment resuspension. The first mechanism has already been discussed in the previous section. As for the second mechanism, organic material stored in the sediments can be mobilized by activity of many deposit feeder species (Rhoads and Boyer 1982; Probert 1984), and the increasing abundance of deposit feeders may have enhanced the release of dissolved organic material from sediments.

Regarding the third mechanism, the shallow and decreasing eelgrass depth limits up to 2008 probably contributed to enhanced sediment resuspension and poor water clarity. Dense eelgrass meadows have a stabilizing effect on sediments by dissipating wave energy and thereby promoting particle trapping and water clarity (Carr et al. 2010). Hence, dense meadows facilitate their own existence and expansion via positive feedback effects (van der Heide et al. 2011; McGlathery et al. 2012). The meadows also stimulate carbon and nutrient retention as well as habitat and biodiversity, and hence, in several ways contribute to resilience and functionality of the coastal ecosystem (Gutiérrez et al. 2011; van der Heide et al. 
2011; McGlathery et al. 2012). By contrast, resuspension of sediments in periods of reduced eelgrass cover, as was the case in Danish coastal waters after decades of substantial eutrophication, hampers reestablishment of the meadows (Carr et al. 2010; Krause-Jensen et al. 2012; Carstensen et al. 2013). Eutrophication also changes the sediment composition towards higher organic content and finer particles which render the sediments less suitable for anchoring and growth of eelgrass (Koch 2001; Valdemarsen et al. 2010; Krause-Jensen et al. 2011). High cover of drifting algae in eelgrass meadows during the 1990s (Rasmussen et al. 2014) may have contributed further to the delayed reestablishment.

A more detailed analysis of changes in the Danish eelgrass meadows showed that the first signs of improvements in depth extension upon reduced nutrient inputs and improved water clarity were observed for the most well-established meadows in the outer parts of the fjords, where the positive feedbacks were likely strongest (Hansen 2012). This pattern is in accordance with the findings of van der Heide et al. (2011) that the seagrass-sediment-light feedback is a dominant mechanism in exposed coastal areas. The well-established meadows also extended to deeper waters where resuspension was likely less pronounced and may have contributed to their faster recovery. In the current study, macroalgal cover responded faster to reductions in nutrient inputs than did eelgrass (Fig. 9), and this difference in response might also be explained by the algal community representing deeper waters $(7 \mathrm{~m})$ and hard bottom substrates where resuspension is less pronounced and water clarity probably responds faster to reduced nutrient levels than at the shallow eelgrass sites. The deeper extension of the macroalgal community is due to the much lower light requirements than for eelgrass (Sand-Jensen et al. 2007). Macroalgae which reproduce via spores also have the capacity to recover faster (from year to year, e.g., Moy and Christie 2012) while eelgrass depends on slow vegetative expansion or sexual reproduction with seedling survival as an important bottle neck (Olesen and Sand-Jensen 1994).

The reduction in filter feeder density, e.g., reduced cover of mussel banks, may also have enhanced sediment resuspension by exposing more of the sediment surface area to near bottom water currents. Moreover, it is known that some deposit feeders by their reworking activities may destabilize the surface sediments (Rhoads and Boyer 1982; Probert 1984). However, more firm conclusions on whether or not destabilization due to deposit feeders is the case here, must await a more detailed study of species composition.

\section{Conceptual Management Framework for Recovery}

Duarte et al. (2009) outlined a range of conceptual models for the degradation and recovery of coastal ecosystems that included trend reversal, shifting baselines, and regime shifts. Our results fit well within this framework by illustrating all these recovery trajectories as explained in detail below (Fig. 10).

Nutrient trends were reversed with a direct and almost proportional response in nutrient concentrations to the nutrient management plans. These results demonstrate that nutrients in coastal ecosystems are tightly coupled to watershed processes and that nutrient concentrations can be controlled quite effectively by regulating the sources. Although our results indicate minor delays in nutrient responses, these time lags are small compared to the time frames of implementing nutrient reduction measures.

Increasing stratification during the study period changed the baseline of the chlorophyll $a$ response by reducing the benthic grazing pressure. This shift in baseline could be due to a change in the regional wind patterns from climate change or it could be part of a decadal oscillation in the dominant summer wind regimes. We do not know if the present frequency of stratification represents a general change or an anomaly. Recovery is likely to accelerate if summer wind conditions increases in the future, since this will increase the benthic filtration and enhance the light regime, allowing eelgrass to spread more widely and establish deeper populations. On the other hand, it is also possible that the generally windier summers of 1980s partly dampened the negative effects of eutrophication, i.e., eutrophication effects would have been much worse if the stratification pattern had been similar to that observed in the most recent decade. Thus, frameworks for nutrient management should also consider changes in other ecosystem pressures, even though some of these might be uncontrollable.

Positive feedbacks between eelgrass distribution, sediment resuspension, and light conditions are likely to maintain a turbid state for longer periods, despite reductions in phytoplankton biomass observed over the last couple of decades. Similarly, an alternative clear state may exist for the same nutrient pressure, sustained by the same positive feedbacks between widespread eelgrass meadows, low sediment resuspension, and clear water. The constant Secchi depth since 1990, while large decreases in nutrient inputs have occurred, suggests that two alternative stable states could exist. Whether the current light regime will remain stable over longer periods of time with the current nutrient pressure is not known, but the recent improvements in eelgrass depth limits may indicate that a transition from turbid to clear water is ongoing. Feedback processes are likely to accelerate recovery, implying that such a transition can happen over shorter periods of time, maybe within a decade. This recovery was even further accelerated with lower frequency of stratification and increasing benthic filtration. Thus, the combination of feedback processes and shifting baselines have delayed eelgrass recovery considerably, but it is plausible that the positive tendency over the last 5 years signals a beginning regime shift towards a clearer state. However, such transition can be sensitive to climatic 
perturbations that may either slow down or accelerate the recovery process. The extent to which important coastal ecosystem components, such as eelgrass meadows, will maintain or even extend their key role in Danish coastal waters is therefore not easily predicted, but requires continued monitoring.

Our analysis is focused on bottom-up effect of nutrients in the control of the coastal ecosystems and has less emphasis on top-down effects of grazing and food web changes as the monitoring data do not allow large-scale analysis of topdown control. We acknowledge that top-down processes via changes in the food web can affect the ecological quality as well (Carpenter et al. 1987; Nielsen and Richardson 1996; Scheffer et al. 2001) via grazing and predation by fish, jellyfish, and zooplankton. While data on the importance of pelagic food webs would have strengthened our analysis of longterm changes, our results strongly support that excessive increases and decreases in nutrient inputs from land have been the key driver of changes in Danish coastal ecosystems.

Acknowledgments This work is a contribution from a funding from the dean at the Faculty of Science and Technology, Aarhus University to Bo Riemann. This work is a contribution from the COCOA project under the BONUS program funded by the EU 7th framework program and the Danish Research Council. We thank all the personnel from regional authorities who collected samples under the Danish Nationwide Aquatic Monitoring and Assessment Program.

Open Access This article is distributed under the terms of the Creative Commons Attribution 4.0 International License (http://creativecommons.org/licenses/by/4.0/), which permits unrestricted use, distribution, and reproduction in any medium, provided you give appropriate credit to the original author(s) and the source, provide a link to the Creative Commons license, and indicate if changes were made.

\section{References}

Andersen, H.E., B. Kronvang, and S.E. Larsen. 2005. Development, validation and application of Danish empirical phosphorus models. Journal of Hydrology 304: 355-365.

Baden, S., A. Emanuelsson, L. Pihl, C.J. Svensson, and P. Åberg. 2012. Shift in seagrass food web structure over decades is linked to overfishing. Marine Ecology Progress Series 451: 61-73.

Blicher-Mathiesen, G., H.E. Andersen, J. Carstensen, C.D. Børgesen, B. Hasler, and J. Windolf. 2014. Mapping of nitrogen risk areas. Agriculture, Ecosystems \& Environment 195: 149-160.

Boesch, D.F. 2002. Challenges and opportunities for science in reducing nutrient over-enrichment of coastal ecosystems. Estuaries 25: 886900.

Boesch, D., E. Burreson, W. Dennison, E. Houde, M. Kemp, V. Kennedy, R. Newell, K. Paynter, R. Orth, and R. Ulanowicz. 2001. Factors in the decline of coastal ecosystems. Science 293: 1589-1590.

Borja, A., D.M. Dauer, M. Elliott, and C.A. Simenstad. 2010. Mediumand long-term recovery of estuarine and coastal ecosystems: patterns, rates and restoration effectiveness. Estuaries and Coasts 33: 1249-1260.

Boström, C., S. Baden, A.C. Bockelmann, K. Dromph, S. Fredriksen, C. Gustafsson, D. Krause-Jensen, T. Möller, S.L. Nielsen, B. Olesen, J. Olsen, L. Pihl, and E. Rinde. 2014. Distribution, structure and function of Nordic seagrass ecosystems: implications for coastal management and conservation. Aquatic Conservation: Marine and Freshwater Ecosystems 24: 410-434. doi:10.1002/aqc.2424.

Carpenter, S.R., J.F. Kitchell, J.R. Hodgson, et al. 1987. Regulation of lake primary productivity by food web structures. Ecology 68: 1863-1876.

Carr, J., P. D'Odorico, K. McGlathery, and P. Wiberg. 2010. Stability and bistability of seagrass ecosystems in shallow coastal lagoons: role of feedbacks with sediment resuspension and light attenuation. Journal of Geophysical Research 115, G03011. doi:10.1029/ 2009JG001103.

Carstensen, J., D.J. Conley, and B. Müller-Karulis. 2003. Spatial and temporal resolution of carbon fluxes in a shallow coastal ecosystem, the Kattegat. Marine Ecology Progress Series 252: 35-50.

Carstensen, J., D.J. Conley, J.H. Andersen, and G. Ærtebjerg. 2006. Coastal eutrophication and trend reversal: a Danish case study. Limnology and Oceanography 51: 398-408.

Carstensen, J., D. Krause-Jensen, S. Markager, K. Timmermann, and J. Windolf. 2013. Water clarity and eelgrass responses to nitrogen reductions in the eutrophic Skive Fjord, Denmark. Hydrobiologia 704: 293-309. doi:10.1007/s10750-012-1266-y.

Carstensen, J., D.J. Conley, E. Bonsdorff, B.G. Gustafsson, S. Hietanen, U. Janas, T. Jilbert, A. Maximov, A. Norkko, J. Norkko, D.C. Reed, C.P. Slomp, K. Timmermann, and M. Voss. 2014. Hypoxia in the Baltic Sea: biogeochemical cycles, benthic fauna, and management. Ambio 43: 26-36.

Carstensen, J., M. Sánchez-Camacho, C.M. Duarte, D. Krause-Jensen, and N. Marbà. 2011. Connecting the dots: responses of coastal ecosystems to changing nutrient concentrations. Environmental Science and Technology 45: 9122-9132.

Cloern, J.E. 2001. Our evolving conceptual model of the coastal eutrophication problem. Marine Ecology-Progress Series 210: 223-253.

Cloern, J.E., A.D. Jassby, J.K. Thompson, and K.A. Hieb. 2007. A cold phase of the East Pacific triggers new phytoplankton blooms in San Francisco Bay. Proceedings of the National Academy of Sciences 104: 18561-18565.

Conley, D.J. 2000. Biochemical nutrient cycles and nutrient management strategies. Hydrobiologia 410: 87-96.

Conley, D.J., J. Carstensen, G. Ærtebjerg, P.B. Christensen, T. Dalsgaard, J.L.S. Hansen, and A.B... Josefson. 2007. Long-term changes and impacts of hypoxia in Danish coastal waters. Ecological Applications 17: S165-S184.

Conley, D.J., H. Kaas, F. Møhlenberg, B. Rasmussen, and J. Windolf. 2000. Characteristics of Danish estuaries. Estuaries 23: 820-837.

Conley, D.J., H.W. Paerl, R.W. Howarth, D.F. Boesch, S.P. Seitzinger, K.E. Havens, C. Lancelot, and G.E. Likens. 2009. Controlling eutrophication: nitrogen and phosphorus. Science 323: 1014-1015.

Danish Referencelaboratory. http://www.reference-lab.dk/ metodedatablade/metodedatablade-kemiske.aspx). In Danish (www.reference-lab.dk).

Duarte, C.M. 1995. Submerged aquatic vegetation in relation to different nutrient regimes. Ophelia 41: 87-112.

Duarte, C.M., D.J. Conley, J. Carstensen, and M. Sanchez-Camacho. 2009. Return to neverland: shifting baselines affect eutrophication restoration targets. Estuaries and Coasts 32: 29-36.

Duarte, C., A. Borja, J. Carstensen, M. Elliot, D. Krause-Jensen, and N. Marba. 2015. Paradigms in the recovery of estuarine and coastal ecosystems. Estuaries and Coasts. doi:10.1007/s12237-013-97509.

Gonzales-Correa, J.M., J.T. Bayle, T.J.L. Sánchez-Lizaso, C. Valle, P. Sánchez-Jerez, and J.M. Ruiz. 2005. Recovery of deep Posidonia oceanica meadows degraded by trawling. Journal of Experimental Marine Biology and Ecology 320: 65-76.

Greening, H.S., L.M. Cross, and E.T. Sherwood. 2011. A multiscale approach to seagrass recovery in Tampa Bay, Florida. Ecological Restoration 29: 1-2. 
Gutiérrez, J.L., C.G. Jones, J.E. Byers, K.K. Arkema, K. Berkenbusch, J.A. Commito, et al. 2011. Physical ecosystem engineers and the functioning of estuaries and coasts. Treatise on Estuarine and Coastal Science 7: 53-81.

Hansen, J.W. (Ed.) 2012. Marine areas 2011 (In Danish). Aarhus University, DCE, 154 pp. - Scientific Report from DCE - Danish Centre for Environment and Energy, no. 34. http://www.dmu.dk/ Pub/SR34.pdf

Henriksen, H.J., L. Troldborg, P. Nyegaard, T.O. Sonnenborg, J.C. Refsgaard, and B. Madsen. 2003. Methodology for construction, calibration and validation of a national hydrological model for Denmark. Journal of Hydrology 280: 52-71.

Jones, H.P., and O.J. Schmitz. 2009. Rapid recovery of damaged ecosystems. PLoS ONE 4(5): e5653.

Josefson, A.B..., and B. Rasmussen. 2000. Nutrient retention by benthic macrofaunal biomass of Danish estuaries: importance of nutrient load and residence time. Estuarine, Coastal and Shelf Science 50: 205-216.

Justíc, D., N.N. Rabalais, and R.E. Turner. 1996. Effects of climate change on hypoxia in coastal waters: a doubled $\mathrm{CO}_{2}$ scenario for the northern Gulf of Mexico. Limnology and Oceanography 41: 992-1003.

Kemp, W.M., W.R. Boynton, J.E. Adolf, D.F. Boesch, W.C. Boicourt, G. Brush, J.C. Cornwell, T.R. Fisher, P.M. Glibert, J.D. Hagy, L.W. Harding, E.D. Houde, D.G. Kimmel, W.D. Miller, R.I.E. Newell, M.R. Roman, E.M. Smith, and J.C. Stevenson. 2005a. Eutrophication of Chesapeake Bay: historical trends and ecological interactions. Marine Ecology Progress Series 303: 1-29.

Kemp, W.M., et al. 2005b. Eutrophication in Chesapeake Bay: historical trends and ecological interactions. Marine Ecology Progress Series 303: 1-29. doi:10.3354/meps303001.

Kemp, W.M., J.M. Testa, D.J. Conley, D. Gilbert, and J.D. Hagy. 2009. Temporal responses of coastal hypoxia to nutrient loading and physical controls. Biogeosciences 6: 2985-3008.

Koch, E.M. 2001. Beyond light: physical, geological, and geochemical parameters as possible submersed aquatic vegetation habitat requirements. Estuaries 24: 1-17.

Krause-Jensen, D., A.L. Middelboe, J. Carstensen, and K. Dahl. 2007a. Spatial patterns of macroalgal abundance in relation to eutrophication. Marine Biology 152: 25-36.

Krause-Jensen, D., J. Carstensen, and K. Dahl. 2007b. Total and opportunistic algal cover in relation to environmental variables. Marine Pollution Bulletin 55: 114-125.

Krause-Jensen, D., J. Carstensen, S.L. Nielsen, T. Dalsgaard, P.B. Christensen, H. Fossing, and M.B. Rasmussen. 2011. Sea bottom characteristics affect depth limits of eelgrass Zostera marina. Marine Ecology Progress Series 425: 91-102. doi:10.3354/meps09026.

Krause-Jensen, D., S. Markager, and T. Dalsgaard. 2012. Benthic and pelagic primary production in different nutrient regimes. Estuaries and Coasts 35: 527-545.

Kronvang, B., H.E. Andersen, C. Borgesen, T. Dalgaard, S.E. Larsen, J. Bøgestrand, and G. Blicher-Mathiasen. 2008. Effects of policy measures implemented in Denmark on nitrogen pollution of the aquatic environment. Environmental Science \& Policy 11: 144-152.

Kronvang, B., J. Windolf, S.E. Larsen, and J. Bøgestrand (in press): Background concentrations and loadings of nitrogen in Danish surface waters. Acta Agriculturae Scandinavica, Section B - Soil \& Plant Science.

Lotze, H.K., M. Coll, A.M. Magera, C. Ward-Paige, and L. Airoldi. 2011. Recovery of marine animal populations and ecosystems. Trends in Ecology \& Evolution 26: 595-605.

Markager, S., and K. Sand-Jensen. 1992. Light requirements and depth zonation of marine macroalgae. Marine Ecology Progress Series 88: 83-92.

McGlathery, K.J., L.K. Reynolds, L.W. Cole, R.J. Orth, S.R. Marion, and A. Schwarzschild. 2012. Recovery trajectories during state change from bare sediment to eelgrass dominance. Marine Ecology Progress Series 448: 209-221.

Moy, F.E., and H. Christie. 2012. Large-scale shift from sugar kelp (Saccharina latissima) to ephemeral algae along the south and west coast of Norway. Marine Biology Research 8: 309-321.

Munkes, B. 2005. Eutrophication, phase shift, the delay and the potential return in the Greifswalder Bodden, Baltic Sea. Aquatic Sciences 67: $372-381$.

Nielsen, E., and K. Richardson. 1996. Can changes in the fisheries yields in the Kattegat (1950-1992) be linked to changes in primary production? ICES Journal of Marine Science 53: 988-994.

Nixon, S.W., and B.A. Buckley. 2002. A strikingly rich zone-nutrient enrichment and secondary production in coastal marine ecosystems. Estuaries 25: 782-796.

Olesen, B., and K. Sand-Jensen. 1994. Patch dynamics of eelgrass Zostera marina. Marine Ecology Progress Series 106: 147-147.

Pearson, T.H., and R. Rosenberg. 1978. Macrobenthic succession in relation to organic enrichment and pollution of the marine environment. Oceanography and Marine Biology: An Annual Review 16: 229-311.

Pedersen, T.M., K. Sand-Jensen, S. Markager, and S.L. Nielsen. 2014. Optical changes in a eutrophic estuary during reduced nutrient loadings. Estuaries and Coasts 37: 880-892. doi:10.1007/s12237-0139732-y.

Petersen, J.K. 2004. Grazing on pelagic primary producers: the role of benthic suspension feeders in estuaries. In Estuarine nutrient cycling: the influence of primary producers, ed. S.L. Nielsen, G.T. Banta, and M.F. Pedersen, 129-152. Dordrecht: Kluwer.

Petersen, J.K., J.W. Hansen, M.B. Laursen, P. Clausen, J. Carstensen, and D.J. Conley. 2008. Regime shifts in a coastal marine ecosystem. Ecological Applications 18: 497-510.

Probert, P.K. 1984. Disturbance, sediment stability, and trophic structure of soft-bottom communities. Journal of Marine Research 42: 893921.

Rabalais, N.N., R.E. Turner, R.J. Diaz, and D. Justic. 2009. Global change and eutrophication of coastal waters. ICES Journal of Marine Science 66: 1528-1537.

Rasmussen JR, K. Dromph, D. Krause-Jensen, and C. Göke. 2014. Reduced cover of drifting macroalgae following nutrient reduction in Danish coastal waters. Estuaries and Coasts, in press.

Riisgård, H.U., P.B. Christensen, N.J. Olesen, et al. 1995. Biological structure in a shallow cove (Kertinge Nor, Denmark) - control by benthic nutrient fluxes and suspension-feeding ascidians and jellyfish. Ophelia 41: 329-344.

Rhoads, D.C., and L.F. Boyer. 1982. The effects of marine benthos on physical properties of sediments: a successional perspective. In Animal-sediment relations: the biogenic alteration of sediments, ed. P.L. McCall and M.J.S. Tevesz, 336. New York: Plenum Press.

Sand-Jensen, K., and J. Borum. 1991. Interactions among phytoplankton, periphyton and macrophytes in temperate freshwaters and estuaries. Aquatic Botany 41: 137-175.

Sand-Jensen, K., T. Binzer, and A.L. Middelboe. 2007. Scaling of photosynthetic production of aquatic macrophytes - a review. Oikos 116: 280-294.

Scheffer, M., S. Carpenter, J.A. Foley, C. Foley, and B. Walker. 2001. Catastrophic shifts in ecosystems. Nature 413: 591-596.

Scheffer, M., and S.R. Carpenter. 2003. Catastrophic regime shifts in ecosystems: linking theory to observations. Trends in Ecology \& Evolution 18: 648-656.

Stæhr, P.A., and J. Borum. 2011. Seasonal acclimation in metabolism reduces light requirements of eelgrass (Zostera marina). Journal of Experimental Marine Biology and Ecology 407: 139-146.

Strickland, J.D.H., and T.R. Parsons. 1972. A practical handbook of seawater analysis. Bulletin of the Fisheries Research Board of Canada 167: $1-310$. 
Taylor, D.I., C.A. Oviatt, and D.G. Borkman. 2011. Non-linear responses of a coastal aquatic ecosystem to large decreases in nutrient and organic loadings. Estuaries and Coasts 34: 745-757. doi:10.1007/ s12237-010-9312-3.

Timmermann, K., G.E. Dinesen, S. Markager, L. Ravn-Johnsen, M. Bassompierre, E. Roth, and J.G. Støttrup. 2014. Development and use of a bio-economic model for management of mussel fisheries under different nutrient regimes in the temperate estuary Limfjorden, Denmark. Ecology and Society 19: 14.

Valdemarsen, T., V. Canal, E. Kristensen, M. Holmer, M.D. Kristiansen, and M.R. Flindt. 2010. Vulnerability of Zostera marina seedlings to physical stress. Marine Ecology Progress Series 418: 119-130.

van der Heide, T., E.H. van Nes, M.M. van Katwijk, H. Olff, and A.J.P. Smolders. 2011. Positive feedbacks in seagrass ecosystems - evidence from large-scale empirical data. PLOS ONE 6: e16504. doi: 10.1371/journal.pone.0016504.
Villnäs, A., J. Perus, and E. Bonsdorff. 2011. Structural and functional shifts in zoobenthos induced by organic enrichment - implications for community recovery potential. Journal of Sea Research 65: 8-18.

Wasmund, N., G. Nausch, and W. Matthäus. 1998. Phytoplankton spring blooms in the southern Baltic Sea-spatio-temporal development and long-term trends. Journal of Plankton Research 20: 1099-1117.

Windolf, J., G. Blicher-Mathiesen, J. Carstensen, and B. Kronvang. 2012. Changes in nitrogen loads to estuaries following implementation of Governmental Action Plans in Denmark: a paired catchment and estuary approach for analyzing regional responses. Environmental Science \& Policy 24: 24-33.

Windolf, J., H. Thodsen, L. Troldborg, N.B. Ovesen, and B. Kronvang. 2011. A distributed modelling system for simulation of monthly runoff and nitrogen sources, loads and sinks for ungauged catchments in Denmark. Journal of Environmental Monitoring 13: 2645-2658. 